\title{
Comparative Analysis of the Industrial Patent Competition Situation-Take Xiamen as an Example
}

\author{
Dan $\mathrm{Li}^{1}$, Hen Tang ${ }^{1}$, Long Cheng ${ }^{2}$ \\ ${ }^{1}$ Intellectual Property Research Center of Jiangsu Province, Jiangsu University, Zhenjiang, China \\ ${ }^{2}$ Jiangsu Hui-zhi Intellectual Property Services Limited, Zhenjiang, China
}

Email address:

lidan@ujs.edu.cn (Dan Li), chenglong@jshzip.com (Long Cheng)

To cite this article:

Dan Li, Hen Tang, Long Cheng. Comparative Analysis of the Industrial Patent Competition Situation-Take Xiamen as an Example. European Business \& Management. Vol. 3, No. 6, 2017, pp. 134-142. doi: 10.11648/j.ebm.20170306.17

Received: November 22, 2017; Accepted: December 27, 2017; Published: January 11, 2018

\begin{abstract}
The global development of regional industry becomes more transparent because of the economic globalization. The development and reform of industrial technology caused by big data analysis makes industries more predictable. Based on the core issue of "patent thicket", this paper constructs an analysis framework of the competitive situation of industrial patents and carries out empirical research, taking Xiamen city as an example, basing on Jiangsu province, Guangdong province and Shenzhen city and with the aid of WIPO "industry - technology" matching table. It shows that compared with the advanced provinces and cities, Xiamen's competitiveness of industrial patent is relatively weak. Most of them are in the state of technological precursor monopoly and exploration of weak competitive technology. Based on the results of case analysis, the paper puts forward setting up the periodic monitoring mechanism of the competitive situation of industrial patents, rationally arranging incentive policies and paying attention to industry development, so as to ensure measures such as the monitoring quality of competitive situation of industrial patents to promote industrial innovation and development.
\end{abstract}

Keywords: Patent Thickets, Competitive Situation of Industrial Patent, Innovation of Industrial Technology

\section{Introduction}

Patent, as a means of stimulating and protecting innovation, is becoming more and more important for the development of industry in the context of current knowledge and economy [1-2]. With the global popularization of intellectual property rules, the patent has become the most important method to protect the technology innovation, especially for technology-intensive industries. Patent level represents the level of technology innovation and plays an important role in the development of industrial economy [3]. Robert solow, as the representative of the new classical economists, listed technological progress separately and regarded it as the most important factor for the contribution to economic growth in his neoclassical growth theory. He put forward the point that "technological progress's important contribution to the economic growth" for the first time and regarded technical progress, labor and capital as the three main factors for economic growth [4]. In high technology industries, the patent has been a characterization of technological progress and become the important factors of production. A growing number of economists began to use the patent instead of the technology to study economic problems [5-6]. At the same time, the influence of patent system on the main characteristic of industrial development has also changed gradually. Along with the institutionalization of market competition, the impact of the development of patent technology on the regional economic activities and competitiveness is more and more important, which leads to the motivation of applying for a patent trending to be capital and legal operation and the protection of government on patent system becoming more and more highlighted. The characteristic that the patent system itself protects technology innovation has made the dissimilation, thus patent's effect of the economic development is not effective, for example "Problem-patent" caused by motivation [7-8] and "Pseudo-innovation" caused by government incentives [9].

In conclusion, this paper puts forward the proposition that "How can we clarify the competitive situation of regional industrial patent under the premise of the questionable patent quality. In the complex pattern of industrial technology 
innovation, we should understand the competition status of industrial patent in the region. And, we should clarify the orientation of industrial technology innovation to promote the development of the industrial innovation". The current studies of patent competition are about a particular industry, exploring from regional comparative perspective, which has a certain application value for regional industrial innovation.

\section{Research Design}

\subsection{Construction of Analysis Model}

\subsubsection{About "Patent Jungle"}

The patent right is a monopoly granted by the state to its inventor in order to stimulate innovation. As a legal exclusive right, the patentee has the right to exclude anyone from using the patent without its permission within the duration of the patent protection. Therefore, in certain technical fields, the patent right is an effective barrier to protect the rights of the patentee. However, the degree of exclusivity of the knowledge assets of different industries is different, and its sensitivity to patents is different [10-11]. The legal exclusiveness promotes the enterprises to apply for more patents in the related field.

In the industries with high sensitive patents, the traditional complex technology, (complex technology), knowledge fragment is more complex and trivial which means we can apply for huge number of patents and the patent rights are interdependent [12]. If it emerges a large number of patents within a narrow technology region, the patents will protect the rights of existing patentees and the patents will also hinder the further development and innovation of the technology, because potential entrants have to pay for patent use to be licensed by the patent holder; And if these patents belong to multiple patent holders, then potential innovators must cross multiple barriers. This greatly aggravates the cost of innovation and causes the waste of social resources, which is the problem of "patent jungle". American economists restate it from an economic point of view as a dense, overlapping network of intellectual property rights for multiple companies [13].

\subsubsection{The Impact of "Patent Jungle"}

In the field of low sensitivity of patent technology, such as pharmaceuticals, patent jungle problem is not outstanding, but in the field of complex technology, semiconductor, telecommunications, computer, etc, for example, the patent right often has overlapping phenomenon, forming the so-called patent jungle. Accumulative innovation (cumulative innovation) is particularly important in the field of complex technology, namely the latecomers' innovation depends on the achievements of predecessors in this field which means new entering enterprises must get many fundamental or blocking patent license in the field of complex technology [14]. In the field of complex technology, the innovation of technology is often based on the predecessors, and the strong patent rights can adversely affect the subsequent innovation due to the protection of technology [15]. In the patent jungle, the obstacles to innovation mainly contains two aspects: (1)
Improving the innovation cost of entrants, including the cost of patent design and the cost of patent technology; (2) Reducing incentives for R\&D investment. For the former, Graevenitz' et al. (2012) study shows that the patent portfolio owned by the enterprise will have different impact on the patent application: companies with more patent portfolios will usually increase the patent application, while companies with small patent portfolios is on the contrary [16]. The result is that the market will be more concentrated, more importantly, squeezing the innovation space of new entrants and vulnerable enterprises, increasing the cost of innovation for entrants. For the latter, Bessen (2003) established the innovation competition model in two companies and found that compared with the patent competition mode of "winner take all" (winner takes all), in the jungle of patents, the method of cross licensing is conventional measures to alleviate the patent jungle problems. Under the situation of cross licensing, innovative achievements will have to be shared with other patent holders, more detailed, the innovators' benefits has suffered damage in the solution which will reduce the incentive for innovation [17]. Moreover, the key factor of enterprise $R \& D$ investment incentive is time leading edge, and the cross-licensing will make the innovation disappear.

\subsubsection{Key Elements of Model Construction}

\section{(1) Industry type}

The accumulation of industry patents and its related development are often associated with the development characteristic of particular industry technology. There are patent strongly dependent industries and the impact of patents in the industry is bigger, such as pharmaceutical, chemical, electronic technology fields are typical patent technology fields with fierce competition. Some other areas, such as mechanical, material and other fields, the patent technology can not fully reflect the characteristics of the technological competition in the industry. Therefore, the analysis of industrial patent competition from the perspective of "patent jungle" should focus on some typical industries with strong patent dependence.

(2) The density of industry patentees

The patentee density, as a typical measure of patent quality in the field of technology, represents the ratio between the number of authorized patents and the corresponding number of ownership in a particular technology field. Obviously, when the patent density is higher, the number of owners on the field is relatively smaller, the monopoly level is higher and the value of patent technology implementation is concentrated, which are relatively ideal state. When the patent density is low, there will be numerous patentees, which trends to the situation of patent jungle. In fact, the innovation activities of patent technology are most likely to suffer from friction and to clamp down on each other in this situation. Therefore, the investigation of patent density should be an important basis for the patent competition situation.

(3) The stock of industrial patents

From the concept of "patent jungle", the basic premise is that a large number of patents have been collected in a certain 
industry or industry technical field. When the number of patents in a particular technology field is still very small, the patentee density is very random and cannot represent typical development of patent jungle. The premise condition of the development of patent jungle should have a certain stock of patents or the effect of the technology market is good enough to when the patentee density can be an important evaluation index.

(4) Analyze and compare the benchmarks

At present, the developed countries are adept in the application of the patent system, and have formed the patent layout in the key technical fields that matches the technological innovation. "Patent jungle" is quite common in the field of industrial technology abroad, although the number of patents effectively increase in recent years in our country, there is still a big gap in the patent application of industries because of the late starting. The phenomenon of "patent jungle" is not common in most industries in China, and it always locates in areas with large industrial economies such as the Yangtze river delta and the pearl river delta. In theory, the development of industrial innovation in China should be based on the advanced industry in developed countries. Through analysis and comparison, the gap and breakthrough can be found and the development path can be determined. At present, in the special stage of China's industrial development, it is more consistent with China's national conditions to compare and analyze the industrial patent competition in the target region based on typical regions and typical industries. At the same time, compared with foreign industries, the same industries have higher comparability and the analysis is more effective.

\subsubsection{Analysis of Model Construction}

To sum up, the frame of analysis model of patent competition for specific industries shown in figure 1 is constructed:

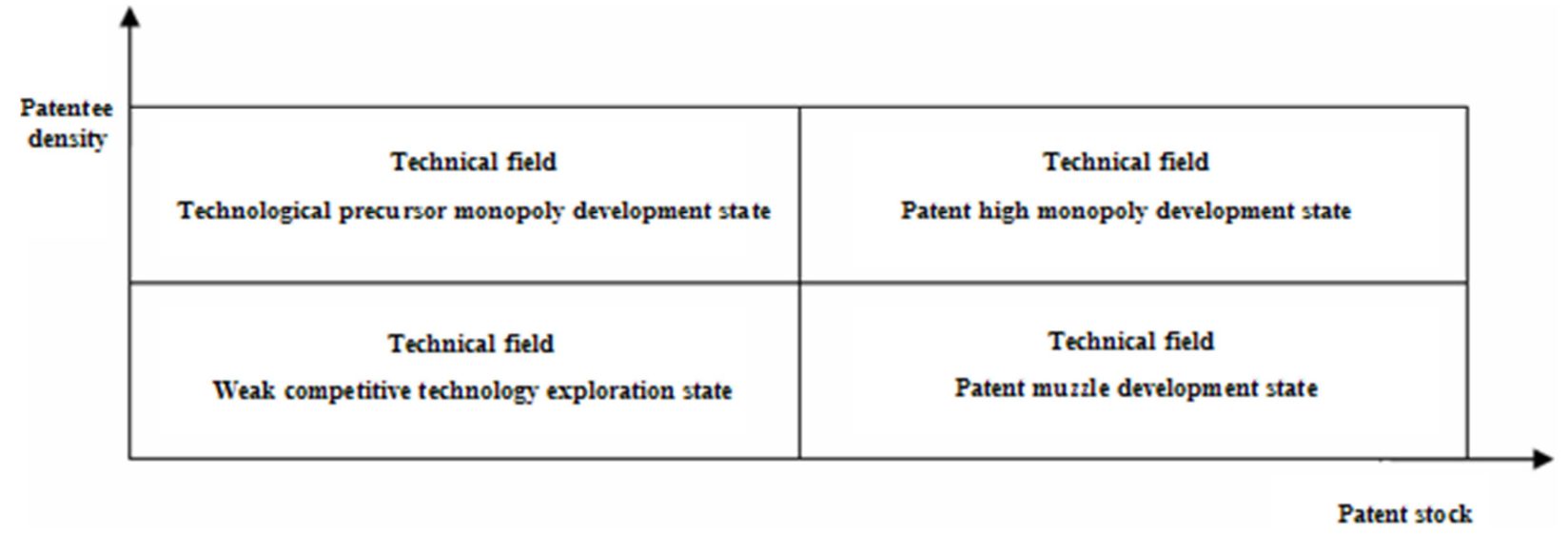

Figure 1. Framework of the analysis model of patent competition in specific industries.

The patent technology field that is in the state of technical control is usually characterized by a large number of patents as well as patentees, which makes the result of low density of the patentee. In contrast, when the patentee density is high and the patent inventory is small, some patentees as the technical leaders have entered the field and some development in the patent technology field. However, the field has not yet entered the state of vigorous market development, so it should be a typical development form in the field of emerging technologies. When there is a large amount of patents in a technical field and the patentee density is also very high, it should be in the state of vigorous development of the market. The market is still dominated by a few patentees, the patentee's competitive position should be very high.

Further, describe the phenomenon of patent competition in different industries: (1) In development state of technical precursor monopoly, the patent stock is small and the patentee density is high, which means the patentee has the advantage of pioneering technology development. (2) In development condition of patent high monopoly, the patent stock is big and the patentee density is high, which means the patentee has the monopolistic competitive advantage in the corresponding field and can also be regarded as the highest status of the current technology competition. (3) In condition of exploration of weak competitive technology, the patent stock is small and the patentee density is low, which means the patentee is in a state of unsystematic technological exploration in the corresponding field and there is no outstanding competitive advantage between different subjects. There is not obvious development trend, which belongs to the chaotic development state of patent technology (4) In development state of patenting, the patent stock is big and the patentee density is low, which means the patentee is in the highly competitive development state in the corresponding field and the patent technology can not play a monopoly role.

\subsection{Determination of Samples}

\subsubsection{The Sample Area}

From 2011 to 2016, the national patent status report showed that Guangdong province, Beijing city and Jiangsu province always ranked the top three. Guangdong province and Jiangsu province, as China's big economic provinces, have been the leaders in industrial and technological innovation. The figure shows the comparison of the main business income of high-tech industries in different provinces and cities in recent years. The high-tech industries of Guangdong province and 
Jiangsu province are significantly better than other provinces and cities in terms of economic scale, partly reflecting the outstanding achievements of industrial technology innovation in the two provinces. Based on this, this project will analyze the competitive situation of industrial patents in Xiamen city referring from Jiangsu province and Guangdong province.,

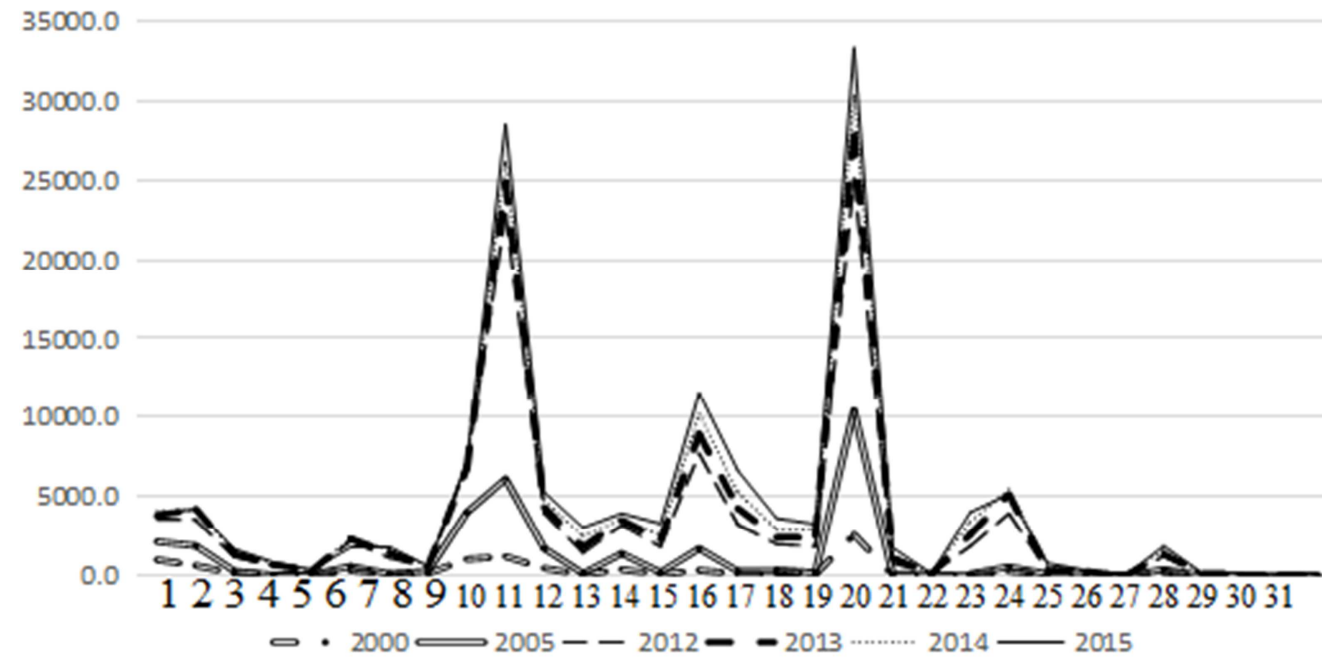

Figure 2. Comparison of main business income of high-tech industries.

1-31 mean Beijing, Tianjin, Hebei, Shanxi, Neimenggu, Liaoning, Jinlin, Heilongjiang, Shanghai, Jiangsu, Zhejiang, Anwei, Fujian, Jiangxin, Shandong, Henan, Hubei, Hunan, Guangdong, Guangxin, Hainan, Chongqing, Sichuan, Guizhou, Yunnan, Xizang, Shanxi, Gansu, Qinghai, Ningxia and Xinjiang

In terms of the selection of specific industries, we focus on patent intensive industries and then conduct comparative analysis of industrial data in Xiamen city, Jiangsu province and Guangdong province, determining the industries with the same or similar statistical caliber (For example, industry name, statistic index, statistical year, etc). Finally, the analysis was carried out in Jiangsu province, Guangdong province and Shenzhen city.

\subsubsection{Sample Industries}

Sample industry has two categories. The first category is based on the world intellectual property organization (WIPO)'s "Last update: February 2016" industry and the sample industry is divided into five major industries and 35 sub-sectors. The second category considers the actual situation of Xiamen city and the industry of Xiamen city is further matched with the WIPO industry. As shown in Table 1, the sample industries contain advanced manufacturing industry and new material industry which serves the local industries of Xiamen city as a benchmark.

\subsection{Analysis Method}

Analyze the related data of industrial patents. The raw data of the patents originates from the patent database issued by the state intellectual property office. The data of industrial patent distribution is matched by the corresponding relationship between industry and international patent classification number by the Ipc8-Technology Concordance established by the world intellectual property organization (WIPO). The patent data of characteristic industries in Xiamen city is determined by Table 1 .

Table 1. The corresponding table of characteristic industries in Xiamen city and WIPO publishing industries

\begin{tabular}{ll}
\hline $\begin{array}{l}\text { Characteristic high-tech } \\
\text { industries in Xiamen city }\end{array}$ & (WIPO) Subdivision industry \\
\hline & $\begin{array}{l}\text { optical; Measurement technology; Biometric analysis technology; The control technology; Medical technology; } \\
\text { Environmental technology; Handling, operation; Machine tools; Engine, pump, turbine; Textile, paper machinery; } \\
\text { Odvanced manufacturing industry special machinery; Thermal processes and equipment; Mechanical components; Transport machinery }\end{array}$ \\
Basic material chemistry; Materials, metallurgy; Surface technology, coating; Microstructure and nanotechnology
\end{tabular}

Analyze the comparison and analysis process. Firstly, when the industry is the basis for the analysis which is industry sample 1, it takes the analysis model of the original industry patent competition as analysis framework. Secondly, in order to improve the effect and pertinence, we should consider the economic dimension of different cities,

The funding for research and the staff size may directly lead to the differences of patent applications between different cities. Therefore, in the strict sense, there will be some errors in judging the competitive situation of industrial patents by combining the industrial patent inventory with the corresponding industry patentee density. In order to eliminate the error, we carry out the standardized treatment of industry patents and the stock of the patentees in different regions based on the model framework of the original patent competition situation, with the aid of statistical data of the Xiamen special economic zone yearbook, Jiangsu statistical yearbook, China statistics yearbook on high technology industries and 
Shenzhen's high-tech industry development situation of statistical data, collecting corresponding economic data of high and new technology industries in Xiamen, Shenzhen and Jiangsu province. Therefore, when the analysis is conducted based on the characteristic industry of Xiamen city, that is the industry sample 2, patent data should be standardized and the method of processing is shown in figure 3 .

\section{Standardized stock of regional industrial patents= Regional ind ustrial output value * Stock of regional ind ustrial patents \\ Note: the patentee density is constant}

Figure 3. The standard method of industrial patent data.

\section{Empirical Results}

\subsection{The Industry Published in WIPO as the Analysis Standard}

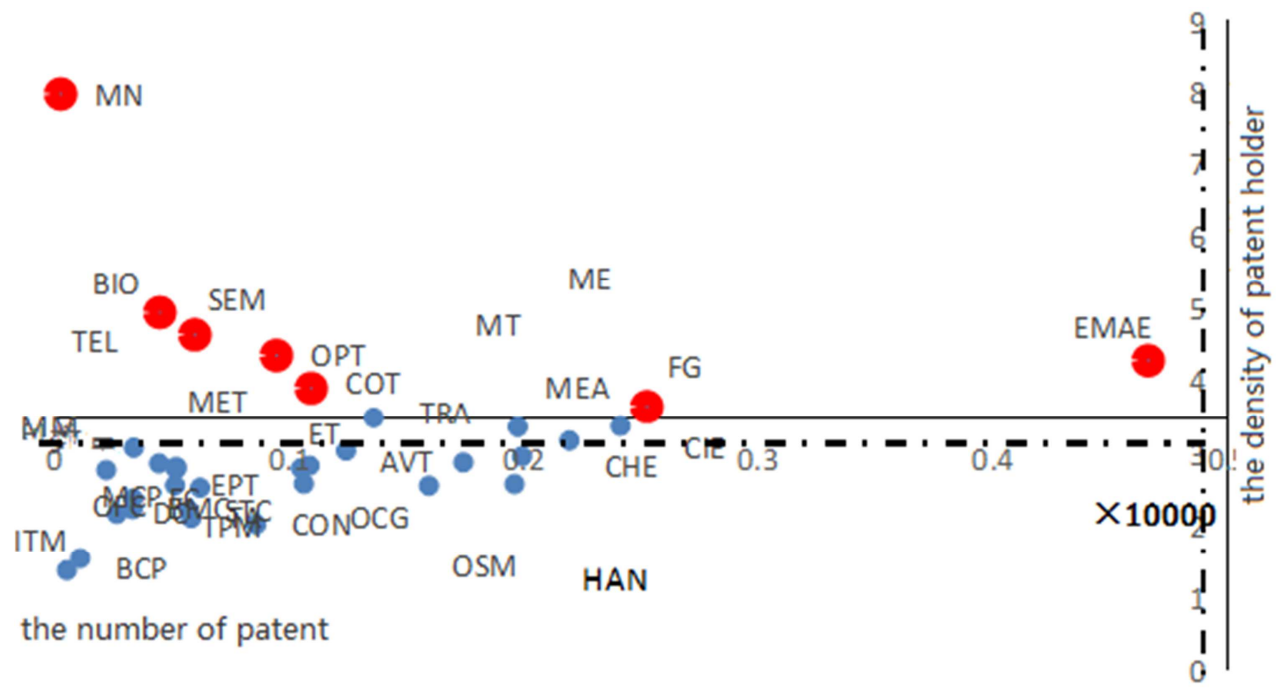

Figure 4. The benchmark comparison chart of subdivided industries in Jiangsu province and Guangdong province (dotted line represents Jiangsu province)

Figure 4 shows the competitive situation distribution of Xiamen's corresponding subdivision industry patents based on the average level of Jiangsu province and Guangdong province. As can be seen from the figure, the various subdivision industries of Xiamen city are in the state of technological predominance and weak competitive exploration. The detailed distribution is shown in table 2

Table 2. The competitive situation distribution of Xiamen's corresponding subdivision industry patents (based on Jiangsu province).

\begin{tabular}{|c|c|c|c|c|c|}
\hline \multicolumn{2}{|c|}{ Technological precursor monopoly development state } & \multicolumn{4}{|c|}{ Technical weak competition technology exploration state } \\
\hline $\begin{array}{l}\text { Subdivision } \\
\text { industry }\end{array}$ & Name of the industry & $\begin{array}{l}\text { Subdivision } \\
\text { industry }\end{array}$ & Name of the industry & $\begin{array}{l}\text { Subdivision } \\
\text { industry }\end{array}$ & Name of the industry \\
\hline $\mathrm{MN}$ & Microstructure and nanotechnology & $\mathrm{OFC}$ & Fine chemical technique & EPT & Engine, pump, turbine \\
\hline $\mathrm{BIO}$ & Biological engineering & AVT & $\begin{array}{l}\text { Audio and video } \\
\text { technology }\end{array}$ & OSM & Other special machinery \\
\hline SEM & Semiconductor technology & MEA & Measurement technology & TPM & Textile, paper machinery \\
\hline OPT & Optical technology & MT & Machine tools & $\mathrm{FC}$ & Food chemistry \\
\hline COT & Computer technology & MET & Medical technology & STC & Surface technology, coating \\
\hline FG & Furniture, games & TEL & communication & $\mathrm{DC}$ & $\begin{array}{l}\text { Digital communication system } \\
\text { technology }\end{array}$ \\
\hline TRA & transport & ET & $\begin{array}{l}\text { Environmental } \\
\text { technology }\end{array}$ & TA & $\begin{array}{l}\text { Thermal processes and } \\
\text { equipment }\end{array}$ \\
\hline CIE & Civil engineering & MCP & $\begin{array}{l}\text { High polymer chemical } \\
\text { polymer }\end{array}$ & $\mathrm{CON}$ & The control technology \\
\hline ME & Mechanical components & OCG & Other consumer goods & BCP & $\begin{array}{l}\text { Basic communication } \\
\text { processing technology }\end{array}$ \\
\hline $\mathrm{CHE}$ & Chemical engineering & HAN & Handling, operation & ITM & $\begin{array}{l}\text { IT management information } \\
\text { technology }\end{array}$ \\
\hline
\end{tabular}


When we takes the average level of Jiangsu province and Guangdong province as the benchmark, four subdivision industries' technology development status including transportation, civil engineering, mechanical components and chemical engineering has changed from the technological precursor monopoly to the Exploration of weak competitive technology which reflects the patent competition is a relative concept. When the standard is different, industry patent competition state will change accordingly. Through further comparison the standards in Jiangsu province and Guangdong province (patent stock: industry patentee density), as shown in figure 4 , the standard of Jiangsu province $(16306,3.179)$ and Guangdong province $(17873,3.502)$ have consistency and the analysis results have a certain credibility.

\subsection{The Characteristic Industries of Xiamen City as the Analysis Standard}

Figure 5 shows the patent competitive situation distribution in the advanced manufacturing industries of Xiamen city which is based on the average level of Shenzhen city. The detailed data is shown in table 3 . Table 3 shows 91 technical fields are in the development state of technological precursor monopoly, including B60C (automobile tyres (manufacture and repair to B29); tyre inflation; tyre replacement; general inflatable elastomer and valve connection; device related to the tire arrangement (tire test to G01M 17/02)) and A43D (shoes or shoes repaired machinery, tools, equipment or methods (sewing to D05B)).

Take the Shenzhen city as the standard( piece, billion)-Advanced manufacturing industry

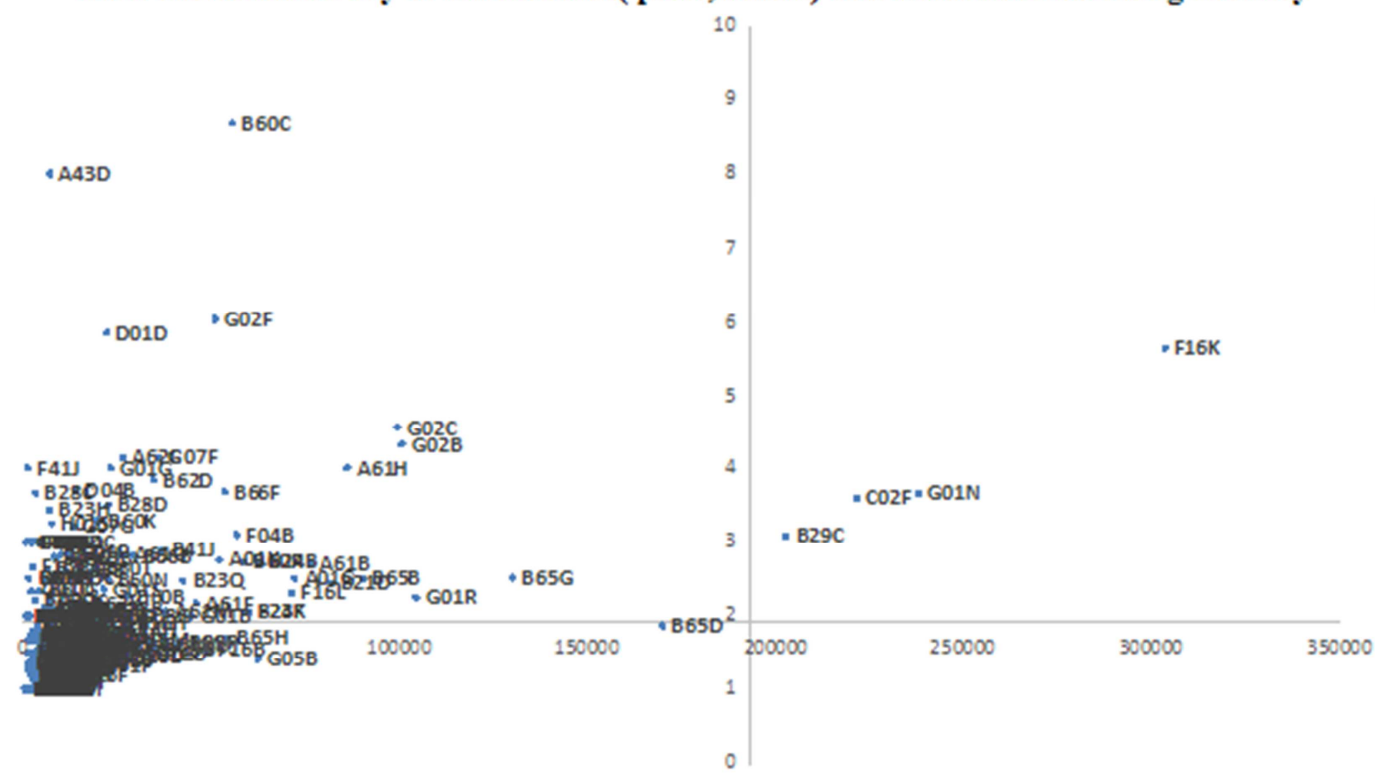

Figure 5. The technological competitive situation distribution of advanced manufacturing industries in Xiamen city.

Table 3. The distribution table of technology competitive situation of advanced manufacturing industries in Xiamen city.

\begin{abstract}
Technological precursor monopoly development state
B60C, A43D, G02F, D01D, A62C, G07F, G01G, F41J, B62D, D04B, B66F, B28C, B28D, B23H, B60K, H01S, G07G, F04B, B64C, B64D, F04F, F02C, F28C, F42D, G04G, B41J, G01P, B60H, A61G, B66B, F04C, B63B, A01K, B24B, B60R, F16T, B60T, B23G, B26B, B23C, F02D, B61L, D02G, D02H, G03G, B60N, B23Q, G01S, B60G, G01Q, B60B, B09C, A22C, A61F, B62K, A21C, F23G, D05B, B23B, F23D, D03D, F15B, A61M, B29D, B23K, F24F, G01B, G08G, F16D, B60S, G01C, F03B, G07D, B27C, B02B, G01T, B21K, B27G, B60M, F02F, F41G, B65G, G01R, G02B, G02C, B65B, A61H, B21D, A61B, A01G, F16L

F28D, F16H, B31B, A01D, F23Q, D04H, B65F, F24H, G01K, B64F, A61J, B24D, A01M, B21B, B62L, G05G, A61L, F25B, F28F, D01F, F24C, B65H, B62J, F03D, B29B, B25J, B63C, D01H, F27B, B25C, F41H, F16M, F04D, B62B, B23P, B41F, B09B, G01M, B60J, F02M, C08J, A61N, G09B, B66C, F16C, F16J, B63H, F16B, E01F, B60L, F41B, B25B, G01J, A23P, B60P, D21H, G01V, A01B, B60D, F02P, G08B, G01L, G03B, G07C, B21C, A61C, F02B, B26D, G05D, C03B, F22D, B60Q, G01D, G05B, B62H, F01D, F23B, B28B, B30B, B23D, F27D, G05F, F01N, F03G, D03J, D04C, F01L, G21F, G01F, B21J, F24J, F42B, A01C, D06H, B21F, B62M, F23J, G03F, B27M, B31F, B60W, F16G, F16F, A23N, B41K, F01P, A41H, F01K, F28G, B26F, B25H, G07B, F17D, B65C, B67C, F24D, G04B, F23C, B24C, F22B, D06M, F16S, B41M, B67B, F16N, B66D, B67D, F17C, G01H, A21B, A62D, B25F, B25G, G12B, A01F, B25D, D06P, D21J, F01M, F02N, F23K, F23L, F23M, B21H, B27B, B27D, B31D, B41C, B60F, D01G, D21B, D21G, F02K, F15D, F23R, G04F, A22B, A46D, A61D, B23F, B27F, B27L, B27N, B41G, B61C, B61D, B61K, B63G, B63J, B64B, D02J, D03C, D06G, D21C, F02G, F03C, F16P, F22G, F23H, F23N, F24B, F28B, F41A, G01W, G04D, G09D, G21C, G21D, B65D
\end{abstract}

Weak competitive technology exploration status

\section{Patent}

high monopoly development state

F16K, G01N, C02F, B29C Patent muzzle development state 
There are four technical fields in the patent high monopoly development state, including F16K (valve; faucet; Cock; Actuating float; Ventilation or aeration device), G01N (test or analysis materials by means of chemical or physical properties the materials (except immunoassays, enzyme or microorganism measurement or test to $\mathrm{C} 12 \mathrm{M}, \mathrm{C} 12 \mathrm{Q})$ ).

There are 189 technical fields in the weak competitive technology exploration state, including F28D (heat exchange equipment not included in other small classes, in which the heat exchange medium not in contact with directly (heat transfer, heat exchange or heat storage material to $\mathrm{C} 09 \mathrm{~K} 5 / 00$; the fluid heater with heat generation device and heat transfer device to F24H; furnace to F27, components of general heat exchange equipment to $\mathrm{F} 28 \mathrm{~F}$ ); general heat storage device or equipment ) and $\mathrm{F} 16 \mathrm{H}$ (transmission devices).

\section{Take the Shenzhen city as the standard( piece, billion)-New material industry}

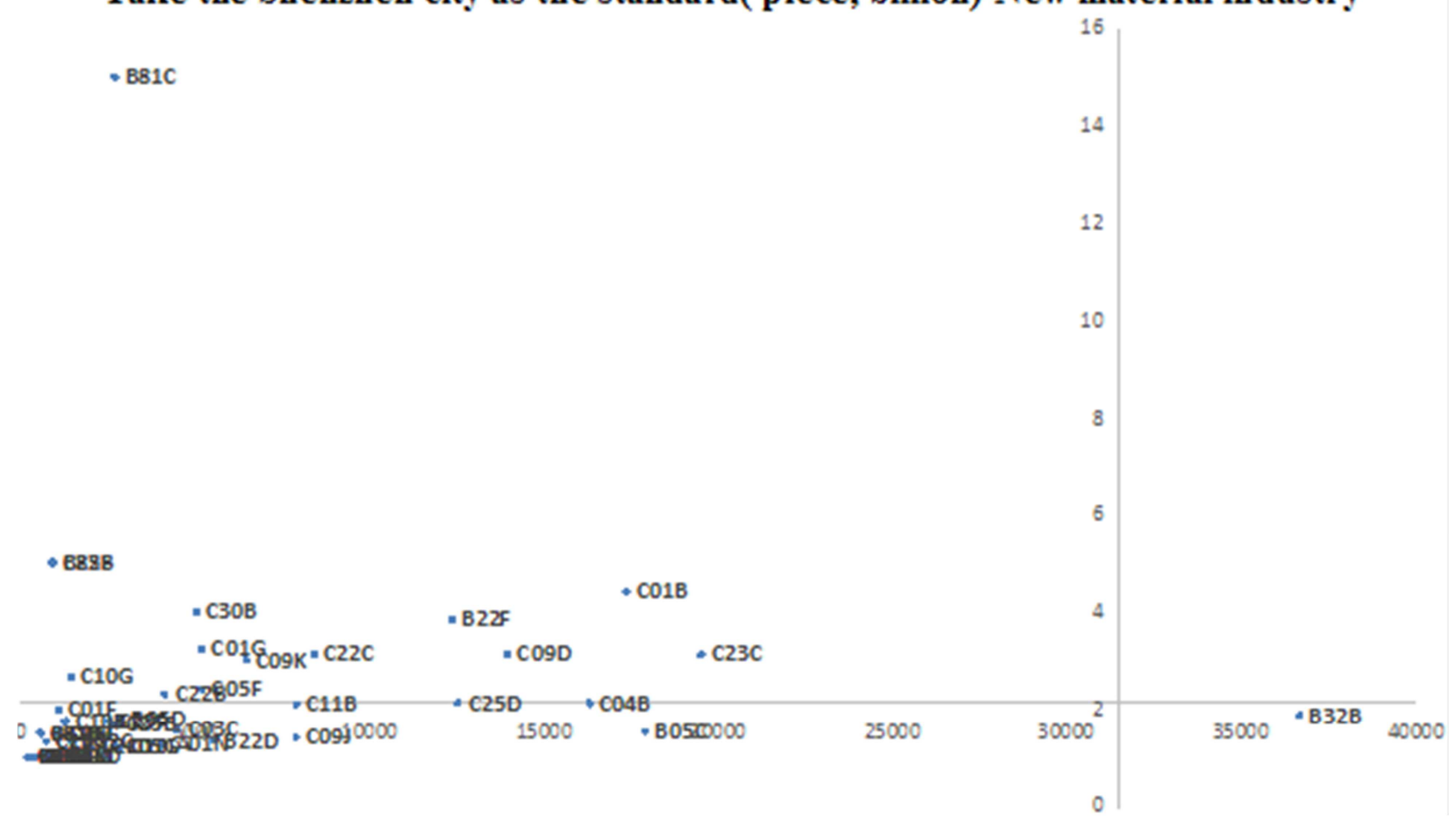

Figure 6. The distribution of technical competition of new materials in Xiamen city.

Figure 6 shows the distribution of patent competition of new material industries in Xiamen city based on the average level of Shenzhen city. Table 4 shows the specific distribution.

Table 4. The distribution table of technical competition of new material industries in Xiamen city.

\begin{tabular}{lc}
\hline Chnological precursor monopoly development state & Patent high monopoly development state \\
\hline $\mathrm{B} 81 \mathrm{C}, \mathrm{B} 82 \mathrm{~B}, \mathrm{C} 25 \mathrm{~F}, \mathrm{C} 01 \mathrm{~B}, \mathrm{C} 30 \mathrm{~B}, \mathrm{~B} 22 \mathrm{~F}, \mathrm{C} 01 \mathrm{G}, \mathrm{C} 22 \mathrm{C}, \mathrm{C} 09 \mathrm{D}, \mathrm{C} 23 \mathrm{C}, \mathrm{C} 09 \mathrm{~K}, \mathrm{C} 10 \mathrm{G}, \mathrm{C} 05 \mathrm{~F}, \mathrm{C} 22 \mathrm{~B}, \mathrm{C} 25 \mathrm{D}$ & \\
$\mathrm{C} 04 \mathrm{~B}, \mathrm{C} 11 \mathrm{~B}, \mathrm{C} 01 \mathrm{~F}, \mathrm{~B} 05 \mathrm{D}, \mathrm{C} 23 \mathrm{~F}, \mathrm{C} 10 \mathrm{~B}, \mathrm{C} 25 \mathrm{~B}, \mathrm{C} 03 \mathrm{C}, \mathrm{B} 05 \mathrm{C}, \mathrm{C} 10 \mathrm{~J}, \mathrm{C} 25 \mathrm{C}, \mathrm{B} 81 \mathrm{~B}, \mathrm{C} 01 \mathrm{C}, \mathrm{C} 21 \mathrm{~B}, \mathrm{C} 09 \mathrm{~J}$, & $\mathrm{B} 2 \mathrm{~B}$ \\
$\mathrm{~B} 22 \mathrm{D}, \mathrm{B} 22 \mathrm{C}, \mathrm{C} 11 \mathrm{C}, \mathrm{C} 23 \mathrm{G}, \mathrm{A} 01 \mathrm{~N}, \mathrm{C} 05 \mathrm{G}, \mathrm{C} 10 \mathrm{~L}, \mathrm{C} 21 \mathrm{D}, \mathrm{C} 11 \mathrm{D}, \mathrm{C} 09 \mathrm{C}, \mathrm{C} 10 \mathrm{M}, \mathrm{C} 09 \mathrm{~B}, \mathrm{~B} 82 \mathrm{Y}, \mathrm{C} 01 \mathrm{D}, \mathrm{C} 05 \mathrm{C}$, & $\mathrm{P}$ \\
$\mathrm{C} 05 \mathrm{D}, \mathrm{C} 06 \mathrm{D}, \mathrm{C} 09 \mathrm{H}, \mathrm{C} 10 \mathrm{C}$ & Patent muzzle development state \\
Weak competitive technology exploration status & \\
\hline
\end{tabular}

There are 15 industrial and technical fields in the technological precursor monopoly development state, including B81C (special devices designed for the manufacture or treatment of microstructures or systems equipment (manufacturing microcapsules or microspheres to B01J 13/02; special method or equipment to manufacture piezoelectric devices, electrostrictive devices or magnetostrictive devices to H01L 41/22)), B82B (through the manipulation of single atoms, molecules or as a collection of tiny atoms or molecules isolated unit of nanometer structure; manufacturing or processing).

There are 34 industrial and technical fields in the weak competitive technology exploration state, including C04B (lime; magnesium oxide; slag; cement; a composition such as mortar, concrete or similar building materials; artificial stone; ceramic (microcrystalline glass ceramic to C03C 10/00); refractory materials (refractory metals alloy to $\mathrm{C} 22 \mathrm{C}$ of); natural stone processing), $\mathrm{C} 11 \mathrm{~B}$ (production, pressing raw materials or extracting from waste materials, refining or preserving fat, fatty substances such as lanolin, fat or wax; essential oil; spices; (Drying oil to C09F)).

B32B (layered products, products of flat or non-flat thin layers, such as foamy, honeycombed thin layers) is in a patented muzzle development state.

To further verify the correctness of the conclusion, this 
article selectes the new materials industry and analyzes the patent competition situation in the corresponding industry technology region based on the benchmark of Jiangsu province, comparing with the analysis results in Shenzhen city.
As shown in figure 5, it can be seen from the figure that the overlap ratio of patent competition of new material industries in Xiamen city is very high.

Table 5. The comparison table of technological competitive situation of new material industries in Xiamen city -- unified dimension (two kinds of benchmarks).

\begin{tabular}{lll}
\hline & Take Shenzhen city as the standard & Take Jiangsu province as the standard \\
\hline $\begin{array}{l}\text { Technological precursor } \\
\text { monopoly development }\end{array}$ & $B 81 C, B 82 B, C 25 F, C 01 B, C 30 B, B 22 F, C 01 G, C 22 C, C 09 D, B 81 C, B 82 B, C 25 F, C 01 B, C 30 B, B 22 F, C 01 G, C 22 C, C 09 D$, \\
state & $C 23 C, C 09 K, C 10 G, C 05 F, C 22 B, C 25 \mathrm{D}(15)$ & $C 23 C, C 09 K, C 10 G, C 05 F, C 22 B(14)$ \\
Weak competitive & $C 04 B, C 11 B, C 01 F, B 05 D, C 23 F, C 10 B, C 25 B, C 03 C, B 05 C$, & $\mathrm{C} 25 \mathrm{D}, C 04 B, C 11 B, C 01 F, \mathrm{~B} 32 \mathrm{~B}, B 05 D, C 23 F, C 10 B, C 25 B$, \\
technology exploration, & $C 10 J, C 25 C, B 81 B, C 01 C, C 21 B, C 09 J, B 22 D, B 22 C, C 11 C$, & $C 03 C, B 05 C, C 10 J, C 25 C, B 81 B, C 01 C, C 21 B, C 09 J, B 22 D$, \\
status & $C 23 G, A 01 N, C 05 G, C 10 L, C 21 D, C 11 D, C 09 C, C 10 M$, & $B 22 C, C 11 C, C 23 G, A 01 N, C 05 G, C 10 L, C 21 D, C 11 D, C 09 C$, \\
Patent muzzle & $C 09 B, B 82 Y, C 01 D, C 05 C, C 05 D, C 06 D, C 09 H, C 10 C(34)$ & $C 10 M, C 09 B, B 82 Y, C 01 D, C 05 C, C 05 D, C 06 D, C 09 H, C 10 C(36)$ \\
development state & $\mathrm{B} 32 \mathrm{~B}(1)$ & \\
\hline
\end{tabular}

te: the coarse italic part is the field of overlap technology.

\section{Conclusions}

When the WIPO is the standard to divide industries and the average level of Jiangsu province is a benchmark, microstructure and nano technology, biological engineering, semiconductor technology, optical technology, electrical / mechanical / instrument / power technology, computer technology, furniture / game, transportation, civil engineering, mechanical components and chemical engineering are in technological precursor monopoly development state, while other fields are in weak competitive technology exploration state. When the average level of Guangdong province is a benchmark, the transportation, the state of civil engineering, mechanical components and chemical engineering transforms from technological precursor monopoly development state to weak competitive technology exploration state, which reflects the differences between two kinds of reference in Jiangsu province and Guangdong province. Guangdong province is better than that of Jiangsu province in transportation, civil engineering, mechanical components and chemical engineering. Through the comparison between two kinds of benchmark, there is the consistency in Jiangsu province (16306-3.179) and (17873, 3.502) Guangdong province and the conclusion is true.

Based on the standard of characteristic industries of Xiamen city and combining with industrial economic data to standardize the industrial patent stock, we found that: (1) In view of the advanced manufacturing industries, there are 91 industrial technology fields in the technological precursor monopoly development state, such as B60C, A43D, G02F, D01D, A62C, G07F, G01G, F41J, B62D, D04B. There are 189 industrial technology fields in the weak competitive technology exploration state, such asF28D, F16H, B31B, A01D, F23Q, D04H, B65F, F24H, G01K, B64F. There are 4 industrial technology fields in the patent high monopoly development state, such as F16K, G01N, C02F, B29C. (2) In view of the new material industries, there are 15 industrial technology fields in the technological precursor monopoly development state, such as $\mathrm{B} 81 \mathrm{C}, \mathrm{B} 82 \mathrm{~B}, \mathrm{C} 25 \mathrm{~F}, \mathrm{C} 01 \mathrm{~B}, \mathrm{C} 30 \mathrm{~B}, \mathrm{~B} 22 \mathrm{~F}, \mathrm{C} 01 \mathrm{G}, \mathrm{C} 22 \mathrm{C}$, C09D, C23C. There are 34 industrial technology fields in the weak competitive technology exploration state, such as C04B, C11B, C01F, B05D, C23F, C10B, C25B, C03C, $\mathrm{B} 05 \mathrm{C}, \mathrm{C} 10 \mathrm{~J}$. B32B industrial technology is in the patent muzzle development state. Furthermore, the new material industry was compared and analyzed with the mean of Jiangsu province as the standard and the mean value of the overlap ratio of the distribution of patent competition reached $93.89 \%$ which was credible.

\section{The Policy Recommendations}

Previous studies have found significant differences in the competitive state of different industries or their different patents. From the comparison between different regions and cities, these differences directly lead to different performance of industrial innovation. In order to confront the real differences and promote the patent effects on supporting the development of the industry, we put forward the following suggestions:

\subsection{Establish a Regular Monitoring Mechanism for Industrial Patent Competition and Support the Decision-Making of Industrial Innovation and Development}

Different areas' industrial advantages are different. We should not only base on the activity and scientific planning, but also actively focus on the development situation of industries in domestic advanced provinces and cities and foreign countries. We should understand the relationship between industrial patents and industrial economic development and timely know the gap between local industries and their patent technology innovation and that of other advanced areas through the establishment of a regular monitoring mechanism for patent competition in industries. We will evaluate the quality of industrial innovation and development, clarify the direction of industrial development and innovation, and make plans about the industrial restructuring and upgrading paths. Based on the monitoring 
results in a timely manner, we will adjust industrial innovation policy and serve the decisions of industry innovation development through tracking and monitoring the industry patent competition situation of single sample and multi-sample industries.

\subsection{Layout the Difference Incentive Policy Rationally to Promote the Development of Equalization}

In the face of the different development status of industrial patents, the policy should be adjusted actively. We should formulate policies in respond to different conditions and promote the balanced development of different industries. Through the guidance of differentiated policies, optimize the allocation of innovative resources and industrial technology, then optimize the industrial structure and accelerate industrial transformation and upgrading. Specifically, if the industries are in the technological precursor monopoly development state, we should increase the intensity of policy incentives, such as increasing funding amount, encouraging investment in research and promoting the integration of service resources. If the industries are in the patent high monopoly development state, we should strengthen the implementation of industrial patents on the basis of innovation incentive; If the industries are in the weak competitive technology exploration state, we should carry out the necessary industrial technology innovation and implementation of policy incentives and timely adjust industrial policies according to the monitoring result of industrial patent competition status; If the industries are in the patent muzzle development state, we should strengthen macro-control, accelerate industrial transformation and guide the healthy competition and development of industries.

\subsection{Focus on the Industry Development and Ensure the Monitoring Quality of Patent Competition}

Economic globalization leads to the global development of regional industries becoming more transparent. With the development of patent system, large data analysis of changes of industry technology development makes most of the industries' development more predictable. Therefore, with the rapid development of industry and technology, it is equally important to remain open to the government's macro-control ability. Local regions should actively focus on the frontier of industry development and obtain the best samples of industrial patent competition situation. Through competitive situation monitoring, we can understand the development of local industry patents timely and effectively. At the same time, we should also establish local industry patent monitoring system as soon as possible and understand the basic data of patent application, authorization, implementation and trading which not only serve the monitoring of patent competition situation but also serve the requirements of the evaluation of industry policies.

\section{References}

[1] Koivisto R, Wessberg N, Eerola A, et al. Integrating future-oriented technology analysis and risk assessment methodologies [J]. Technological Forecasting \& Social Change, 2009, 76 (9): 1163-1176.

[2] Xu Qiaoling. Empirical research on the relationship between patent development and industrial development of high-tech industries $[\mathrm{J} / \mathrm{OL}]$. Scientific and technological progress and countermeasures, 2013, 30 (04): 60-63.

[3] Zhang Huiying, Wei Yanhui. Research on the multi-effect relationship between the patent system and the high technology industry [J]. Economic restructuring, 2015, (04): 116-122.

[4] Solow R M. Growth theory. An exposition. [J]. Oup Catalogue, 2000, 22 (4): 1016.

[5] Zheng Yu. Knowledge flow and patent efficiency of high technology industry in China [J]. Exploration of economic problems, 2014, (07): 63-70.

[6] Chen Xin, Liu Lina. Economics analysis of monopoly of patent union [J]. Exploration of economic problems, 2005, (12): 42-44.

[7] To Promote Innovation: The Proper Balance of Competition and Patent Law and Policy [J]. Berkeley Technology Law Journal, 2004 (1): 309.

[8] Mou Lili. Research on the relationship between patent application motivation, behavior and performance of high-tech enterprises [D]. Dalian university of technology, 2011.

[9] Zhang Hanguo. The problem of patent administrative confirmation system and its solution [J]. Intellectual property, 2016, (03): 111-116.

[10] Mansfield E. Patents and innovation: An empirical study [J]. Management Science, 1986, 32 (2): 173-181.

[11] Levin R C, Klevorick A K, Nelson R R, et al. Appropriating the returns from industrial $\mathrm{R} \& \mathrm{D}[\mathrm{J}]$. Brookings Papers on Economic Activity, 1987: 121-136.

[12] Rycroft R W, Kash D E. The Complexity Challenge: Technological Innovation for the 21 st Century [J]. Research-Technology Management, 1999, 43 (2): 60-61.

[13] Shapiro C. Navigating the patent thicket: cross licenses, patent pools, and standard-setting [J]. Innovation Policy and the Economy, 2001, 1 (1): 119-150.

[14] Shapiro C. Navigating the Patent Thicket: Cross Licenses, Patent Pools, and Standard Setting [J]. Social Science Electronic Publishing, 2000, 1 (Volume 1): 119-150.

[15] Galasso A, Schankerman M. Patents and Cumulative Innovation: Causal Evidence from the Courts [J]. Quarterly Journal of Economics, 2014, 130 (1).

[16] Von Graevenitz G, Greenhalgh C, Helmers C, et al. Trade Mark Cluttering: An Exploratory Report [M]. 2012.

[17] Bessen J. Patent Thickets: Strategic Patenting of Complex Technologies [J]. Ssrn Electronic Journal, 2002. 